\title{
LAVE CAVES OF KILIMANJARO. MAWENZI LAVA TUBES
}

\author{
Clive Ward
}

\begin{abstract}
ABSTRACT

This is the first short report on the exploration of lava tubes in the upper part of Kilimanjaro. The area seems to be extremely interesting from vulcanospeleological point of view
\end{abstract}

Keywords: vulcanospeleology, lava tubes, Kenya

Kilimanjaro is situated approximately 100 kilometres East of the Rift Valley. Geologists believe that the volcano origin was associated with forces that created the Rift System. The main reasons being that the massive is made of lava similar to eruptions in the rift and formed during the same period of time.

The Base of the present massive extends 80 X 40 kilometres in an East-Southeast direction. There were a number of vents involved in the construction of the initial volcano that is now Kilimanjaro, little is known of earlier stages as out pouring of lava mask these preceeding phases.

Activity became concentrated in three main centres. The first major activity was at Shira, followed by Mawenzi and the last centre was Kibo. At present Shira is considerably eroded and reaches a height of $4006 \mathrm{~m}$, only the southern and western rim remains of a collapsed caldera, Mawenzi to the east by contrast is very spectacular with numerous-pinnacles and huge crags, stands at $5149 \mathrm{~m}$. Kibo at $5895 \mathrm{~m}$, formed between Mawenzi and Shira is considered to be the most recent, continued to grow after volcanic activity ceased on Mawenzi. Although dormant, fumaroles in the inner crater are evident. Recent volcanic eruption may have taken place within the last three hundred years.

Evidence of lava tubes from reports indicates an extensive system thousands of years ago in the region of the Horombo Hut Complex $(3720 \mathrm{~m})$. The writer has investigated the area and found remains of vertical walls, slightly curved in places of up to twelve metres high. A small stream runs after the rains down one such collapsed tube and the sewage drainage from the complex past another. Although it is possible that past flows from Kibo would have extended to Horombo area the directional flow and situation appear to indicate that they originate from Mawenzi.

A hearsay report of a tube or tubes extending down to Lake Chala on the KenyaTanzania border is unconfirmed. Numerous blisters or gas bubbles are found, particularly on the Northern slopes from Shira to Mawenzi. Many in the past have been used for bivouacking by mountaineers.

On 15th August, 1995, the writer approached Mawenzi from the North ascending the Northern Valley on a lava ridge west of Tarn Valley and discovered a tube entrance measuring approximately $1.5 \mathrm{~m} \mathrm{X} 1.5 \mathrm{M}$. A survey revealed a 41 metre tube running down stream in Northwest direction. The top end closed by a latter lava flow. (Fig. 1). Situated S $03^{\circ} 04301 \mathrm{E} 037^{\circ} 27020$.

\footnotetext{
- Cave Exploration Group of East Africa - P.O. Box 47363 - Nairobi, Kenya.
} 


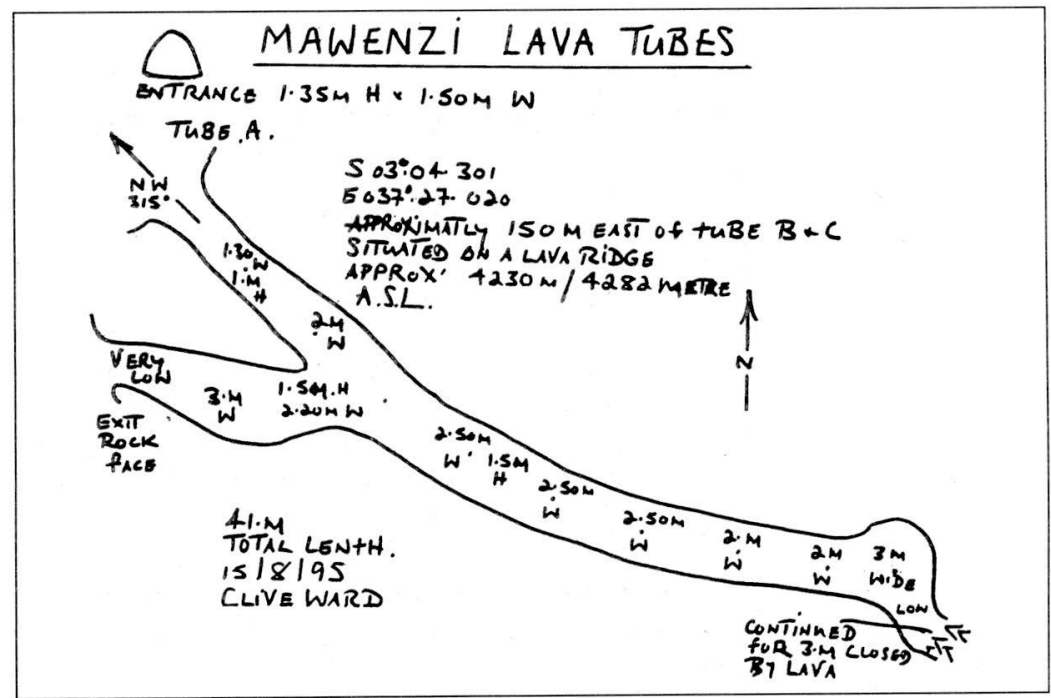

Fig. 1- Sketch of the lava tube A

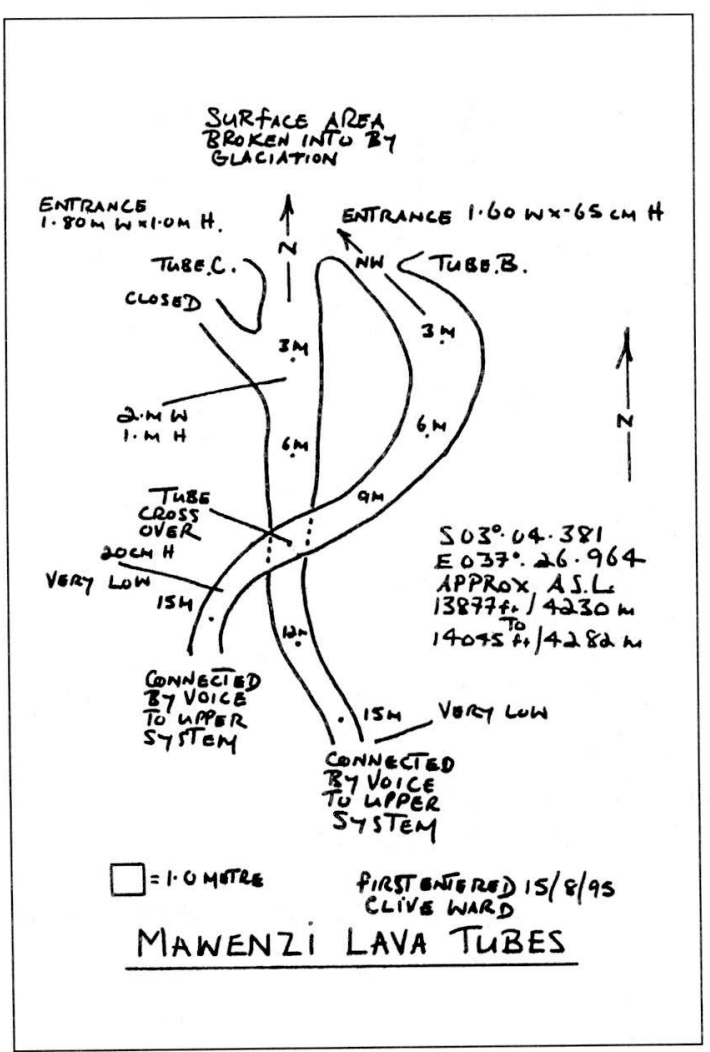

Fig. 2- Sketch of the lava tubes B and C. 
From the entrance of Tube A, 150 metres west and $50 \mathrm{~m}$ higher across a shallow valley which forms the upper extremity of Northern Valley two more entrances were discovered. Discernible from the ridge above Tube A, two classic tubes can be ascended for $15 \mathrm{~m}$ until they become too restricted to continue. Tube $\mathrm{B}$ and Tube $\mathrm{C}$ appear to cross over each other. (fig. 2 \& 3) situated S $03^{\circ} 04381$ E $037^{\circ} 26964$.

Twenty five metres higher and slightly to west another entrance can be found. Tube D (Fig. 4) is far more intricate and has been voice connected to Tube B and C. The combination of the tubes various passages amount to $79.50 \mathrm{~m}$ of passage. The area of tubes are at the altitude of between $4230 \mathrm{~m}$ and $4280 \mathrm{~m}$ A.S.L.

Other small tubes can be found to the west and south but extend no more than a few meters, often obstructed by subsequent flows. One such formation is seen near a campsite on a low bluff, one kilometre away in line with fore mentioned and $100 \mathrm{~m}$ higher to the South. At the base of North West Ridge of Mawenzi. Extensive glaciation during the Pleistocene epoch is still evident as polishing and striations can clearly be seen on surface rock. It appears that all entrances of these tubes were the result of glacier erosion.

In general the direction of tube flow is from South to North and would suggest at one time a tube swarm originated from the Mawenzi vent, most of which no longer exist due to substantial erosion at the time when the cone was striped away.

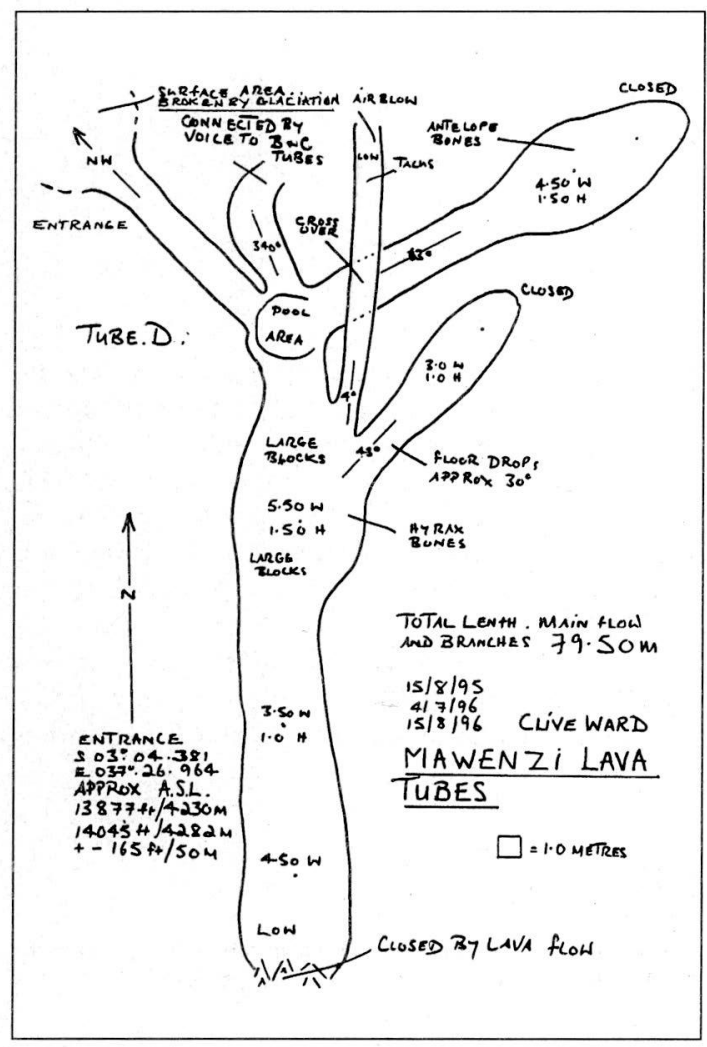




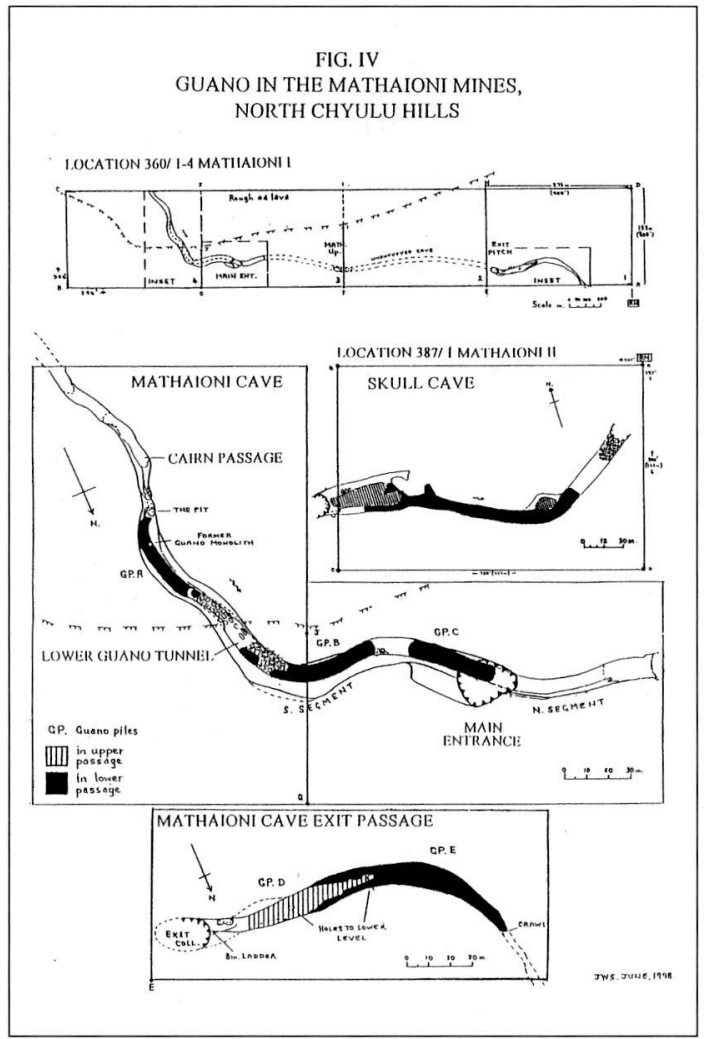

Fig. 4- Sketch of the lava tube E.

Further surface survey between $4000 \mathrm{~m}$ and $4500 \mathrm{~m}$ may uncover more formations but it is doubtful any significant will be found. A collapsed entrance of one small tube to the West of B, C, and D could prove interesting but major excavation would be required.

However, on 2nd August 1996 a large tube was discovered on the Northern Slope of Mawenzi at the altitude of $3780 \mathrm{~m}$. (Map E) situated S $03^{\circ} 02802 \mathrm{E} 037^{\circ} 26409$.

Tube E runs continuous south to north approximately Northeast $40^{\circ}$ for $160 \mathrm{~m}$ and in some sections is $12 \mathrm{~m}$ wide and $3 \mathrm{~m}$ high. From the Kilimanjaro map alignment one can speculate that this tube is related to the system above (A, B, C, and D) some 2.5 kilometres distant. The intermediate county is deeply scored by old glacial riverbeds and in places lower than incline of the tube, so the continuation up hill for any appreciable distance is unlikely. Nevertheless, this area holds the most promise for further discoveries.

\section{REFERENCES:}

SAMPASON, D.N. 1991 The Geology and Volcanology of Kilimanjaro Guide Book to Mount Kenya and Kilimanjaro, edited by Iain Allan. Published by The Mountain Club of Kenya, Nairobi, p.191. 